Extended Abstract for:

49th AIAA/ASME/SAE/ASEE Joint Propulsion Conference and Exhibit

San Jose Convention Center , San Jose, CA, 15-17 July 2013

\title{
Development and Testing of a Green Monopropellant Ignition System
}

\author{
Stephen A. Whitmore, Associate Professor \\ Daniel P. Merkley, Graduate Research Assistant \\ Shannon D. Eilers, Graduate Research Assistant \\ Michael I. Judson, Graduate Research Assistant \\ Mechanical and Aerospace Engineering (MAE) Department \\ Utah State University, UMC 4130, \\ 4130 Old Main Hill \\ Logan Utah, 84322-4130 \\ And \\ Terry L. Taylor, Asst. Manager / Technology Transfer Lead \\ NASA Marshall Spaceflight Center
}

November 7, 2012

\section{Introduction}

This paper will detail the development and testing of a "green” monopropellant booster ignition system. The proposed booster ignition technology eliminates the need for a pre-heated catalyst bed, a high wattage power source, toxic pyrophoric ignition fluids, or a bi-propellant spark ignitor. The design offers the simplicity of a monopropellant feed system features non-hazardous gaseous oxygen $(G O X)$ as the working fluid. The approach is fundamentally different from all other "green propellant" solutions in the aerospace in the industry. Although the proposed system is more correctly a "hybrid" rocket technology, since only a single propellant feed path is required, it retains all the simple features of a monopropellant system. The technology is based on the principle of seeding an oxidizing flow with a small amount of hydrocarbon. ${ }^{1}$ The ignition is initiated electrostatically with a low-wattage inductive spark. Combustion gas byproducts from the hydrocarbon-seeding ignition process can exceed $2400 \mathrm{C}$ and the high exhaust temperature ensures reliable main propellant ignition. The system design is described in detail in the Hydrocarbon-Seeded Ignition System Design subsection.

\section{Background and Literature Review}

This section will discuss the current state of the art for hydrazine-based monopropellant systems, and motivate the need for "green" alternatives. Currently available options will be considered, and the operational readiness for these options will be described. A thorough literature review of several promising "green” monopropellant options will be presented. Issues associated with operational readiness of the most promising options will be presented.

\section{A. Current State of the Art for Monopropellants}

Hydrazine $\left(\mathrm{N}_{2} \mathrm{H}_{4}\right)$ is by far the most commonly used propellant for primary spacecraft propulsion and attitude control thrusters. Hydrazine thrusters, which typically consist of an electric solenoid valve, a pressurant tank, and a catalyst bed of alumina pellets impregnated with iridium (Shell $\left.405^{\circledR}\right)^{2}$, are feature a simple design architecture, are highly reliable, and offer reasonable performance. In a typical design the catalyst initiates an exothermic decomposition of the hydrazine to produce ammonia, nitrogen, and hydrogen gases with approximately $1600 \mathrm{~kJ} / \mathrm{kg}$ of heat. Although hydrazine decomposition using the Shell 405 catalyst can be performed with no additional heat input to the catalyst, typical designs pre-heat the catalyst bed to insure more reliable ignition and consistent burn profile. In preheated configurations vacuum specific impulse $\left(I_{s p}\right)$ greater than 220 seconds can be achieved.

Unfortunately, hydrazine is a powerful reducing agent that poses serious environmental concerns. Hydrazine is extremely destructive to living tissues, and is a probable human carcinogen. Exposure produces a variety of adverse systemic effects including damage to liver, kidneys, nervous system, and red blood cells. ${ }^{3}$ In addition to these 
biological and toxicological impacts, hydrazine presents significant environmental dangers for the spacecraft and launch vehicle. As a chemical prone to rapidly decompose or explode when struck, vibrated, or otherwise agitated, hydrazine is listed among the most sensitive shock-sensitive chemicals by the US Department of transportation.,

Most significantly, hydrazine has a moderately high vapor pressure at room temperature, approximately 1000 $\mathrm{kPa}$ (145 psia). For many applications a high storage vapor pressure is a good propellant feature because it offers the option of delivering the propellant to the combustion chamber using only its natural vapor pressure and offers a potential for further reduction of the system simplicity. ${ }^{6}$ Unfortunately, because of this higher vapor pressure, hydrazine fumes significantly at room temperature and presents a high risk as a respiratory hazard. All hydrazine servicing operations must be performed with the use of Self Contained Atmospheric Protective Ensemble (SCAPE) suits.

Although procedures are in place to allow hydrazine to be managed safely on tightly controlled military reservations and at government-operated launch facilities; the toxicity and explosion potential of hydrazine requires extreme handling precautions. Increasingly, with a growing regulatory burden, infrastructure requirements associated with hydrazine transport, storage, servicing, and clean up of accidental releases are becoming cost prohibitive. As space flight operations continue to shift from government-run organizations to private companies and universities operating away from government-owned test reservations, servicing payloads requiring hydrazine as a propellant becomes operationally infeasible. Extreme handling precautions generally do not favor hydrazine as a propellant for secondary payloads.

A recent study by the European Space Agency's European Space Research and Technology Center (ESA/ESTEC) has identified two essential design elements to achieving low cost space access; 1) Reduced production, operational, and transport costs due to lower propellant toxicity and explosion hazards, and 2) Reduced costs due to an overall reduction in subsystems complexity and overall systems interface complexity. ${ }^{7,8}$ This study showed the potential for considerable operational cost savings by simplifying propellant ground handing procedures. A non-toxic, stable "green" alternative for hydrazine is clearly desirable.

\section{B. Hydrazine Replacement Monopropellant Options}

A useful monopropellant replacement for hydrazine must be chemically and thermally stable (for storage), but must easily decompose and have good combustion properties. Cryogenic or high freezing point propellants requiring temperature control are not appropriate space propulsion applications. Although mass-specific impulse is important, volume-specific impulse (density impulse) is an even more important consideration, and a high propellant storage density is preferred. Most importantly the propellant must be sufficiently stable to allow technicians and engineers to safely work with the propellant.

Hydrogen Peroxide $\left(\mathrm{H}_{2} \mathrm{O}_{2}\right)$ is sometimes used as an oxidizing agent for bipropellant systems, and is currently being proposed as a "less toxic" alternative to hydrazine. ${ }^{9}$ Unfortunately, $\mathrm{H}_{2} \mathrm{O}_{2}$ offers a significantly lower overall performance than hydrazine with vacuum $I_{s p}$ slightly below 170 seconds. More importantly propulsion-grade solutions of $\mathrm{H}_{2} \mathrm{O}_{2}$ have an even higher room temperature vapor than hydrazine, approximately $1200 \mathrm{kPa}$ (175 psia). Thus, while not as toxic as hydrazine, peroxide still presents a significant respiratory hazard. Propellant grade peroxide solutions are also unstable and present a moderate explosion risk. ${ }^{10}$ The reduced performance, coupled with the still significant objective and health hazards, do not favor hydrazine as a "green" alternative to hydrazine.

For the past 15 years the US Department of Defense (DoD) and the Swedish Space Corporation (SSC) subsidiary ECological Advanced Propulsion Systems (ECAPS) have been pursuing green-propellant alternatives based on aqueous solutions of ionic liquids. Ionic liquids are water-soluble substances that normally exist in solid form at room temperature, but melt below the boiling point of water. When dissolved in water these materials exhibit very strong ion-to-ion interactions. Two of two of the currently most promising ionic liquid replacement options for hydrazine are Ammonium Dinitramide $(A D N)^{11,12}$ and Hydroxylamine nitrate $(H A N) .{ }^{13,14} A D N$ melts at approximately 90-03 C, and HAN melts at approximately 44-45 C.

In solid form both ADN and HAN are highly energetic salts with both reducing and oxidizing components. Consequently, in solid form both materials are unstable and potentially explosive. Thus as mentioned in the previous paragraph, for propellant applications both ADN and HAN are used as a used in concentrated aqueous solutions to order to limit the explosion potential. ${ }^{15}$ In typical applications a fuel component such as methanol is added to the solution to increase the propellant performance. Because these propellants are mixed in aqueous solutions, they possess a very low vapor pressure at room temperature, and do not present a respiratory hazard. Thus servicing operations can be performed with the use of SCAPE suits. This low vapor pressure is one of the primary reasons that 
these propellants are considered to be significantly less hazardous than either hydrazine or peroxide.

The manufacturing process for ADN was classified until 1989 when Bottaro, et al, at the Stanford Research Institute (SRI) ${ }^{16}$ independently synthesized ADN. ${ }^{17}$ Currently ADN is manufactured and marketed commercially by EURENCO Bofors, Karlskoga, Sweden and Alexandria VA, USA. The Swedish Space Corporation (SSC) and the Swedish Defence Research Organization (FOI) developed ADN into a liquid monopropellant. The liquid propellant blend is composed of an ionic aqueous solution (10\% water) of ADN (65\%) with methanol (20\%) as a fuel, and ammonia (5\%) as the solution stabilizer. The high performance green propellant (HPGP) is marketed under the product name LMP-103S by the SSC subsidiary, ECological Advanced Propulsion Systems (ECAPS). Moog Space and Defense Group and Alliant Techsystems (ATK) have partnered with ECAPS to make LMP-103S available to the US spacecraft market. ${ }^{18}$

LMP-103S propellant blend is catalytically decomposed to produce water vapor and approximately $2000 \mathrm{~kJ} / \mathrm{kg}$ of heat. In August 2011, ECAPS announced the results of a year-long series of in-space tests of a 1-N thruster, as implemented on the Prisma spacecraft platform, comparing their High Performance Green Propellant (HPGP) to hydrazine. The comparisons claimed that HPGP delivered equivalent-to-superior performance. ECAPS has claimed that their 1-N thruster has achieved a TRL level of 7.0 following this spaceflight demonstration. ${ }^{19,20,21}$ The opportunity to fly the HPGP system served as means to flight demonstrate the new propulsion technology, but also served as a demonstration of how to incorporate system level aspects to the spacecraft level design. Implementation of the 1-N HPGP propulsion system solved issues with respect to five main system level interfaces namely, thermal, power, shock, vibration, and plume effects. ECAPS reported a mean in-space $I_{s p}$ exceeding 220 seconds for the Prisma flight experiment.

The Naval Ordnance Station, Indian Head, MD developed a number of HAN-based liquid monopropellants for use in artillery guns for the US Army. ${ }^{22}$ Three of these formulations were designated as LP1846, LP1845 and LP1898 where concentrated HAN is mixed as an aqueous solution with tri-ethanol-ammonium nitrate (TEAN, $\left(\mathrm{OHCH}_{2} \mathrm{CH}_{2}\right)_{3} \mathrm{NHNO}_{3}$ ) or diethyl-hydroxyl-ammonium nitrate (DEHAN, $\left.\left(\mathrm{CH}_{3} \mathrm{CH}_{2}\right)_{2} \mathrm{NHOHNO}_{3}\right)^{23,24,25,26}$ In these formulations HAN serves as the oxidizing agent, the TEAN/DEHAN components act as fuel, and water is the solvent and buffering agent. The Fuel- rich components are added in the blend to achieve higher energy release and higher flame temperature. Of these propellant formulations LP1846 was the most highly developed and tested.

Aerojet Corporation of Redmond Washington (Formerly the PRIMEX Corporation) conducted alternative development activities where the fuel components of LP1846 were replaced with Glycine $\left(\mathrm{C}_{2} \mathrm{H}_{5} \mathrm{NO}_{2}\right){ }^{27}$ The Aerojet HAN-glycine (HANGLY26) formulation emphasized compatibility with existing hydrazine (SHELL 40R®) catalyst beds and was design to have a low combustion temperature, less than $1100 \mathrm{C}$. HANGLY26 decomposes with an exhaust temperature similar to hydrazine, but produces exhaust products with a significantly higher molecular weight; thus HANGLY26 has a lower $I_{s p}$ than hydrazine (190 seconds). Because of its significantly greater density, HANGLY26 does have greater volumetric impulse efficiency than hydrazine. In this formulation sufficient water was added to keep the combustion temperature below $1100 \mathrm{C}$. This approach was selected to allow an up-front focus on propellant and thruster development rather than a lengthy catalyst development program. ${ }^{28}$ Higher performing propellants that replace the glycine fuel component with methanol are under development. One formulation, designated as HAN 269MEO, has achieved a vacuum $I_{s p}$ near 270 seconds.

\section{Current State of the Art for Ionic-Liquid Combustion Initiation}

Unfortunately, because of the high water content, both ADN and HAN-based propellants aqueous ionic liquid solutions of are notoriously hard to ignite. Typically, propellant combustion ignition is achieved by one of five means, 1) one or multiple pyrotechnic charges, 2) plasma torch, 3) electric spark plugs with bi-propellant oxidizer and fuel injectors, 4) pyrophoric ignition featuring hypergolic bi-propellants, 5) catalytically dissociated monopropellants, Pyrotechnic or "squib" ignitors are one-shot devices, and are most frequently used to ignite solidpropellant rocket motors. Squib-based systems cannot be used for multiple motor ignitions. Squib ignitors are also susceptible to the Hazards of Electromagnetic Radiation to Ordnance (HERO) ${ }^{29}$, and large pyrotechnic ignitors present a significant operations hazard. Plasma torches are devices for generating a directed flow of plasma, and have been effectively used for gas turbine engines and supersonic combustion ramjets for ground test articles. ${ }^{30}$ Typically these devices are bulky and require a significant power input, and are generally ill-suited for spacepropulsion applications. Hypergolic bi-propellants, pyrophoric liquids like Triethylaluminum-Triethylborane (TEATEB), and monopropellants like hydrazine offer very simple design solutions and can be used for multiple re-starts. SpaceX originally considered a torch-ignitor for the Merlin Engine, but down-selected to TEA-TEB instead because of the complexity of the torch-ignition design. ${ }^{31}$ Historically, most LOX/RP engines, such as the Saturn V F-1, have 
used TEA-TEB as the ignition source. Unfortunately, like hydrazine, this class of propellants presents the extreme disadvantage of being highly toxic and difficult to work with during ground processing. As mentioned previously, the 2003 ESA study (Ref. 8) strongly recommends against toxic and hazardous propellants.

Thus catalytic ignition remains the method of choice for both ADN and HAN-based propellant formulations. Development of a room-temperature catalyst capable of withstanding combustion temperatures exceeding $1300 \mathrm{C}$ remains a major challenge, and unfortunately, the "holy grail" of a durable, highly active catalyst that can decompose water/ionic liquid/propellant blends at low temperatures, but can survive at high temperatures in an acidic and oxidizing environment. has yet to be achieved.

\section{Previous Catalyst Development for ADN and HAN-based Green Propellants}

ECAPS has developed a proprietary catalyst bed for decomposing the LMP-103S monopropellant, and this catalyst bed (catbed) has been demonstrated to be capable of surviving more than 30 minutes of collected burn time and multiple restarts. A major disadvantage of the ECAPS design is the requirement to preheat the catbed to at least 350 C before ignition can occur. For the Prisma flight the Maximum load during the catalyst pre-heating is 9.25 Watts, and 8.3 Watts during the thruster firing. Mean power consumption during firing is 7.3 watts. A 10-Watt heater was installed in the Prism spacecraft. Depending on the relative sun angle the duty cycle of the heater varies from 67 to $93 \%$. The time required for $9.25 \mathrm{~W}$ catbed preheating to $340 \mathrm{C}$ in flight varied from $600 \mathrm{~s}$ to $720 \mathrm{~s}$. Operationally preheating time is set conservatively to 30 minutes before enabling the thruster for firing. Because of the potential for freezing the water component of HPGP, the average temperature of the propellant tank was maintained at an operating temperature near $20 \mathrm{C}$.

Similarly, Zube and Wucherer ${ }^{32}$ have developed a temperature resistant, Iridium-based catalyst for high performing HAN-mixtures that included HAN269MEO, and a HAN, aminoethylamine-trinitrate (TRN3), water mixture. Of primary interest in this effort was the development of the catalyst-support material to which a active Iridium catalyst is affixed. Two ceramics, zirconium diboride $\left(\mathrm{ZrB}_{2}\right)$ and zirconium carbide $(\mathrm{ZrC})$, were found to be sufficiently robust to extend the test time to a point where the catalyst material was no longer the time limiting factor. These tests allowed significant burn times, greater than 5 minutes, and a large number of starts, greater than 20. Thus, for the first time, HAN thruster performance above $250 \mathrm{~s}$ measured $I_{s p}$ was achieved on a repeated basis without the handicap of frequent catalyst change. Unfortunately, like the ECAPS catbed, the Iridium/zirconate catalysts still required a significant preheat, up to $400 \mathrm{C}$ to achieve stable and smooth combustion.

Courthéoux et al. (2002) ${ }^{33}$ used a batch reactor to investigat both thermal and catalytic decomposition of binary HAN/water solutions. A primary objective of this work was to investigate the effects of various catalyst bed architectures. In these tests Courthéoux and his team evaluated HAN/water solutions with different HAN concentrations of $20 \%, 60 \%$, and $83 \%$ by weight. These $20 \%, 60 \%$, and $83 \%$ solutions were shown to thermally dissociate at temperatures of $173 \mathrm{C}, 170 \mathrm{C}$, and $135 \mathrm{C}$, respectively. In all cases the non-catalyzed HAN solution would not thermally dissociate until all of the water had vaporized and the liquid HAN droplets were allowed to come into close proximity. Two catbet architectures with platinum (Pt) deposited on alumina $\left(\mathrm{Al}_{2} \mathrm{O}_{3}\right)$ and silicadoped alumina $\left(\mathrm{Al}_{2} \mathrm{O}_{3} \mathrm{Si}\right)$ were demonstrated to reduce the dissociation temperature of the $83 \%$ HAN solution to temperatures slightly above the boiling point of water, 110-115 C.

Recently, Oommen et al. (2011) 34 $^{34}$ reproduced Courthéoux's results for HAN/water solutions using a catalyst with iridium coated $\gamma$-alumina pellets. The experiments demonstrated that catalytic activity occurs at temperatures below the boiling point of water, even for aqueous blends containing low weight percentages of HAN. These tests demonstrated that catalytic HAN decomposition can occur with liquid water still present in the mixture.

Unfortunately, the presence of a fuel component in the HAN mixture significantly increases the dissociation temperature of HAN-based solutions. Ren et al. $(2006)^{35},(2007)^{36}$ investigated various precious metal catalysts and concluded that an Iridium/silicon-dioxide $\left(\mathrm{Ir} / \mathrm{SiO}_{2}\right)$ catalyst was the most active and achieved ignition of an $80 \%$ HAN/water solution at room temperature $\left(40 \mathrm{C}\right.$ ). Even after 20 successive injections, the $\mathrm{Ir} / \mathrm{SiO}_{2}$ catalyst was still active. When the same catalyst was applied to HANGLY26, there was no catalytic activity at room temperature. Ren et al. speculate that the lack of activity was due adsorption and site-blocking on the catalyst surface by the glycine component of the propellant mix. When the catalyst was preheated by nitric acid, room temperature ignition of HANGLY26 was achieved, but with a significant ignition delay; however, it is very likely, that the nitric acid used to pre-heat the catalyst spontaneously reacted with the glycine to initiate the decomposition process, and that no actual catalycity occurred. 


\section{E. Electrolytic Decomposition of HAN-based Propellants.}

Several authors including Risha ${ }^{37}$, Meng ${ }^{38}$, Kare ${ }^{39}$, and $\mathrm{Kuo}^{40}$ have examined the electrolytic decomposition of HAN-based monopropellants. The motivation of these researchers was to circumvent many of the previouslydescribed difficulties with catalyst beds for HAN-based propellants. Risha's initial experiments investigated the ignition characteristics of LP 1846 liquid propellant at room conditions using electrolysis. This study indicated that it is possible to initiate electrolytic HAN decomposition at near room temperature, but with considerable time delay. The time delay to peak power (reactivity) decayed exponentially from 160 seconds to 2-3 seconds with an increase in the input voltage from 7 to 12 VDC. Beyond 12 VDC, the time delay dependency became less significant and appeared to remain constant.

Meng and Kare followed up Risha's study with a numerical study designed to develop detailed numerical models of the electrolytic dissociation process of HAN-based propellants. Their studies were conducted to investigate the effect of electric current, voltage, volume, initial temperature, and HAN concentration on the ignition time delay. Their results indicate that compared with the pure thermal decomposition process, electric current significantly enhances HAN decomposition. They predict that ignition time delay is decreases with increase in current, temperature, and increasing HAN concentration, and increase linearly with the volume of fluid being dissociated.

Kuo verified the predictions of Meng and Kare experimentally. Kuo also investigated the combined-electrolytic and catalytic ignition for HAN269MEO15 using the Shell 405® catalyst to establish the feasibility of roomtemperature ignition. The electrolytic decomposition initiated the reaction and dominated at a lower temperature. As the temperature was increased, catalytic decomposition dominated the reaction. Combustion remained incomplete as indicated by the presence of $N O$ and a much lower reaction temperature of $800 \mathrm{C}$ compared to the adiabatic flame temperature of HAN269MEO15 of 1929 C. Significant delays were experienced.

$\mathrm{Wu}$, et al. (2008) ${ }^{41}$ have developed and tested an low temperature co-fired ceramic (LTCC) electrolytic-ignition HAN-monopropellant micro thruster. The microthruster was successfully ignited with a voltage input of 45 Volts, and a thrust output of approximately $200 \mathrm{mN}$ was measured. Energy input requirements and ignition delays were found dependent on the type of HAN-based propellant used, the voltage potential, and the size of the electrodes within the combustion chamber. Ignition was achieved with energy input as small as 1.9 Joules, while ignition delays as short as $1 / 4^{\text {th }}$ second were observed. When ignition was rapid, some cracking of the thruster body was observed. This thruster design takes advantage of the observation that ignition delays decrease linearly with the volume of fluid being decomposed (Ref. 38); thus very small electrolytic thrusters can be ignited with minimal ignition delays.

\section{Hydrocarbon-Seeding Ignition System Design}

The proposed alternative design for igniting aqueous ionic liquid-based propellants builds on the work of $\mathrm{C}$ Courthéoux (Ref. 33), Risha (Ref. 37), and Wu (Ref. 41). Courthéoux demonstrated that significant energy input was required to thermally dissociate binary HAN/water solutions with up to $387 \mathrm{Watts} / \mathrm{g} / \mathrm{sec}$ of heat input required. Even higher heat inputs are required to dissociate ternary solutions that include a fuel components. Risha demonstrated that a significantly large power source is required if HAN-based propellants are to be dissociated without a long time delay. Thus Wu's electrolytically ignited thruster design is limited to very small propellant mass flows and thrust levels.

The proposed ignitor design produces a very high power output, but is initiated using a low-wattage inductive spark. The design is adapted from a micro-hybrid thruster originally developed for stand-alone space propulsion applications. In this design a small section of solid acrylonitrile butadiene styrene $(A B S)$ thermoplastic acts as a seedling material to initiate combustion within an oxidizing flow. An inductive spark vaporizes a small amount of the solid $A B S$ while the oxidizer flows across the fuel grain surface. Although the process is easily to implement technically, the chemistry of the "hydrocarbon seeding" process is extremely complex and a detailed analytical model has yet to be developed. The authors believe that the spark-ablated ABS fuel "seeding vapor" plus residual energy from the spark are sufficient to trigger localized combustion along the surface of the porous ABS fuel grain. The heat released from this localized reaction in turn vaporize more fuel and a sustained combustion reaction is rapidly achieved. At stoichiometric oxidizer to fuel (O/F) ratios, exhaust byproducts has been measured to exceed $2400 \mathrm{C}^{42}$ 


\section{F. Acrylonitrile Butadiene Styrene (ABS) as the Hydrocarbon Seeding Fuel Element}

Multiple materials including acrylic, hydroxyl terminated polybutadiene (HTBP), polyvinyl chloride ( $P V C)$, and $A B S$ were investigated as potential materials for hydrocarbon seeding. It was discovered that $A B S$ has several unique properties that make it the preferred material for hydrocarbon seeding. Although $A B S$ burns with slightly less energy than the traditional legacy hybrid rocket fuel $H T P B$; the combustion by-products have a lower molecular weight, and the resulting specific impulses are nearly identical. (Ref. 42) Unlike acrylic, $P V C$ or $H T P B$, which are thermo-

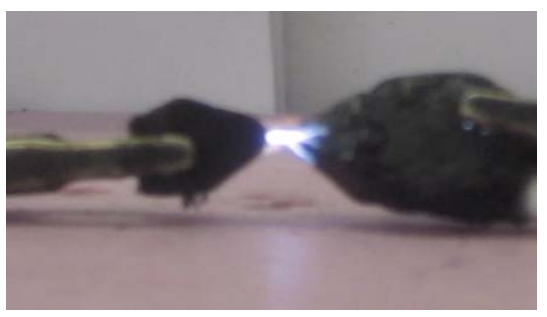

Figure 1. Inductive Spark Across Two ABS Test Segments. setting materials, $A B S$ is a thermoplastic that melts before vaporizing when subjected to heat. This property makes $A B S$ the materials of choice for additive manufacturing (rapid prototyping) machines. Because $A B S$ can be formed into a wide variety of shapes using modern rapid prototyping techniques, it is possible to embed complex, high-surface area flow paths within the fuel grain. ${ }^{23}$ These embedded flow paths cannot be achieved with thermosetting materials that are cast around mandrels and tooling that must be removed once the material is set.

Also, because $A B S$ melts before vaporizing when subjected to heat, a liquid film layer is produced along the length of the fuel port, and this film layer has the effect of providing a significant amount of film cooling. This insulating layer directs the heat of combustion toward the nozzle exit, allowing the external motor case to remain cool during the burn. ABS has a very high structural modulus (2.3 GPa) and tensile yield strength (40 $\mathrm{MPa}$ ), approximately $38 \%$ of aluminum. In any design consideration, the relative strength and insulation properties of the ABS seeding material will allow the fuel element to take a significant portion of the ignition chamber pressure load which reduces the wall thickness requirements and reduces the volumetric requirements for the system.

Most importantly, $A B S$ plastic has a very high dielectric strength and can withstand up to $53.1 \mathrm{kV} / \mathrm{mm}$ (of linear length). ${ }^{43}$ This dielectric value is significantly higher than air $(3 \mathrm{kV} / \mathrm{mm})$. A small segment of $A B S$ material possesses very high current impedance, allowing significant power to be dissipated before the material breaks down. The charge buildup electrifies the grain until a spark jumps the gap across the ignitor fuel port. This spark locally ionizes the oxidizer flow, which reacts with the small amount of solid fuel vaporized from the surface (by the dissipated power), initiating the dissociation/combustion process. Figure 2 shows a high-tension inductive spark arcing across two small $A B S$ test segments.

$A B S$ is widely mass-produced for non-combustion applications including household plumbing and structural materials. More than 1.4 billion $\mathrm{kg}$ of $A B S$ material were produced by petrochemical industries worldwide in $2010^{18}$. $A B S$ plastics are readily shaped into complex geometries using techniques such as extrusion, injection molding, and additive manufacturing (rapid prototyping). The $A B S$ materials possess an extreme tolerance to harsh environmental conditions and have a very long, stable shelf life. Tests have shown that essentially no adverse out-gassing occurs under near-vacuum conditions.

\section{G. Hydrocarbon-Seeded Micro-hybrid Demonstration Prototype}

A low Technology Readiness Level (TRL 2-3) prototype demonstrating the hydrocarbon-seeding concept has been built and tested in the Chimaera Propulsion Test Lab at Utah State University. Figure 2 shows an exploded view of the prototype unit. The figure includes a standard AA battery for scale. The unit features a miniature $A B S$ fuel grain fabricated using a Stratasys Dimension ${ }^{\circledR}$ 3-D Fused Deposition Model (FDM) printer. The current path from input to ground is forced through the mini- $A B S$ fuel grain. The oxidizer flow path of this image is from left to right, and the current flow is from right to left. The high voltage connection is on the downstream side of the $A B S$ grain segment and drops to ground on the upstream end. This particular design operates at $860 \mathrm{kPa}$ (125 psia) chamber pressure with an oxidizer mass flow of $15 \mathrm{~g} / \mathrm{s}$. The produced thrust level is approximately $9 N$ (2 lbf).

The hydrocarbon-seeding grain for this prototype unit features a simple cylindrical oxidizer flow port. To date no optimization study has been performed to identify the best grain geometry for electrolytic ignition. Fortunately, because the grain segments are fabricated using rapid-prototyping technology, changing the grain geometry is as simple as modifying the 3-D printer CAD-file. Originally the unit was tested using a commercially procured "stun gun," but was eventually replaced by a more precise current-limited laboratory high-voltage power supply.44 The power supply is current limited at $14.5 \mathrm{~mA}$, and is capable of delivering a maximum of 150 watts at 10,000 VDC. During the demonstration tests, it was determined that ignition can be achieved with as little as 8-9 watts at 
approximately $1000 \mathrm{VDC}$. Here the current enters the high-tension lead, and then conducts along the surface of the $A B S$ grain segment before jumping the gap to produce the high-voltage spark. The micro-hybrid thruster prototype has been pulse-fired up to 27 consecutive 1-second burns on a single ABS grain segment. The inset picture of Figure 3 shows the micro-hybrid thruster firing during a 1-second pulse firing from one of the initial demonstration tests. The $2.5 \mathrm{~cm}$ grain segments used for this prototype unit have typical impedances exceeding $1 \mathrm{M} \Omega$.

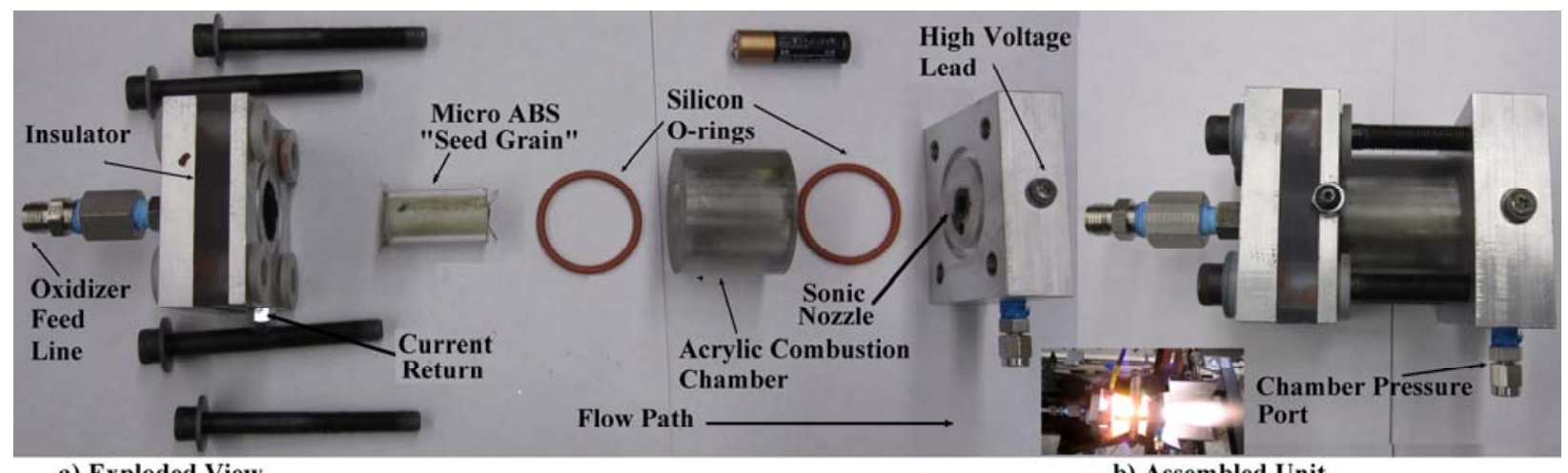

a) Exploded View

Figure 2. “Hydrocarbon Seeded” Micro-hybrid Thruster Prototype.

\section{H. Hydrocarbon-Seeded Ignitor Prototype}

The micro-hybrid prototype was adapted as a non-pyrotechnic, multi-use ignitor for a medium-scale 98-mm hybrid motor system. Figure 3 shows the ignitor firing during initial evaluating tests. Figure 4 shows an exploded view of the test 98-mm motor, motor cap detail, and the ignitor interface. The 98-mm hybrid motor was adapted from a commercially available Cesaroni ${ }^{\circledR}$ solid-rocket $98-\mathrm{mm}$ motor ${ }^{45}$ case by replacing the original ejection charge on the motor cap with a single port oxidizer injector and two ignitor ports. The

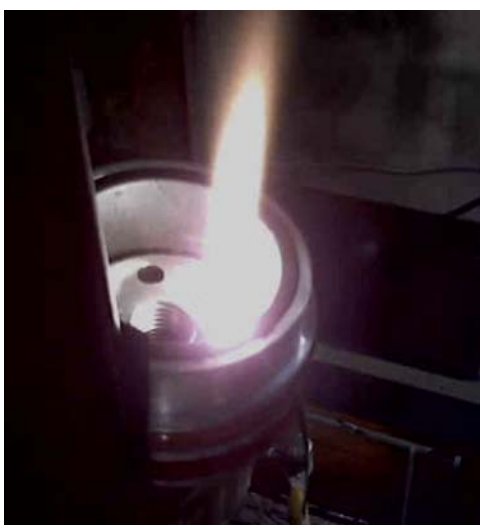

Figure 3. Ignitor Evaluation Tests hydrocarbon-seeded ignitor replaces one of the single-use solid-propellant (pyrotechnic) ignitors formerly used to ignite the 98-mm hybrid motor. The other ignitor port was plugged and unused for these demonstration tests. The hybrid motor uses $\mathrm{N}_{2} \mathrm{O}$ as the oxidizer and main fuel grains are composed of either $A B S$ or $H T P B$.

The system depicted in Fig. 4 was used to successfully ignite the 98-mm motor 4 consecutive times during two separate tests with no hardware changes or propellant additions. The micro-hybrid tests were performed in the Utah State University Jet Engine Test Cell using an existing test Infrastructure. ${ }^{46}$ The motor cap is wired to the high voltage return (and very strongly to ground) so that the entire voltage drop occurs across the $A B S$ seed-grain spark gap -between the high voltage pass-through in the ceramic insulator and the high voltage return. The ignitor oxidizer flow valve was closed as soon as the motor pressure reached $2500 \mathrm{kPa}$ (290 psi) psi to avoid any potential backflow. A backflow check-valve was also installed in the ignitor oxidizer feed line.

Figure 5 shows a functional diagram of the test setup used for the 98-mm motor tests. The ignition system for this motor is extremely simple, consisting of an oxidizer supply, flow regulator, run valve, back flow valve, power supply, trigger relay, and the ignitor assembly. For each burn the ignitor oxidizer flow was synchronized with the high voltage source using a computer-controlled high-voltage relay. The main oxidizer flow was initiated 100 to $250 \mathrm{~ms}$ after the high voltage was applied to the ignitor. The main motor tube is insulated from the high voltage by the ceramic shield surrounding the seeding fuel element until the voltage drops across the spark gap in the grain.

In order to avoid any issues associated with a potential "hard start," the oxidizer flow valve was opened $250 \mathrm{~ms}$ after electrical power was delivered to the fuel grain. Combustion latencies from oxidizer valve opening to full ignition were times to be less than $10 \mathrm{msec}$. For the $98 \mathrm{~mm}$ motor ignition tests the ignitor burn was preset to terminate 0.5 seconds after initiation. The main motor burn continued for 2 seconds after the ignitor flow was terminated. Collected data show the high voltage supply at maximum current output $(14.5 \mathrm{~mA})$ and the ignition voltages varied from 1500 VDC for the first ignition -- before the ignitor grain surface has charred -- to 700 VDC 
for the 4th ignition. The maximum observed spark energy for ignition was 12.3 Joules at an average power input of 8-9 watts. The resulting heat output energy from the thruster is approximately $7.14 \mathrm{kWatt}$ per $\mathrm{g} / \mathrm{s}$ of exit massflow. For these demonstration tests the ignitor produced approximately $8 \mathrm{~g} / \mathrm{s}$ of massflow and produced approximately 28,500 Joules of energy during the $1 / 2$ second burn time.



Figure 4. Hydrocarbon-Seeded Ignitor Interface to 98-mm Hybrid Motor. 


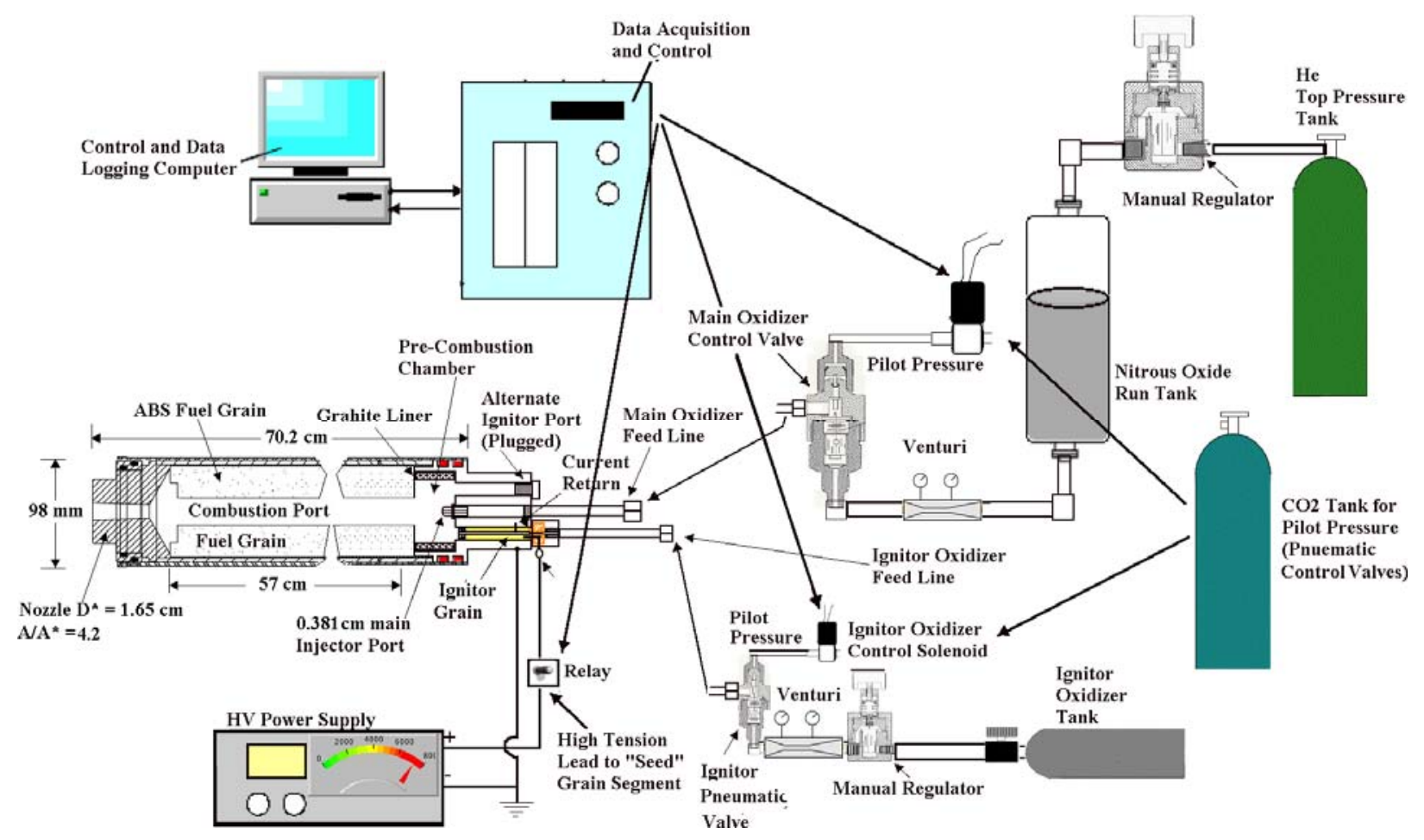

Figure 5. Schematic of Apparatus Used for 98--mm Hybrid Motor Ignition Tests.

\section{HAN Dissociation Experiment}

This paper will present results from an experiment designed to demonstrate that the micro-hybrid ignitors can be used to thermally dissociate a $24 \% \mathrm{HAN} /$ water solution at room temperatures without preheating. Initial analytical models of the dissociation process have predicted that a $24 \%$ HAN/water binary solution flowing at 80 $100 \mathrm{~g} / \mathrm{sec}$ and producing $100 \mathrm{~N}$ (24 lbf) of thrust can be heated to $180 \mathrm{C}$ within one second using dual ignitors identical to the design of Fig. 5. A 24\% HAN solution is the highest commercially available concentration that can be shipped as a non-hazardous material using conventional freight. If the $24 \%$ solution can be thermally dissociated, then it can be concluded that aqueous solutions with a higher HAN concentration or HAN/water/fuel mixtures can also be ignited using the hydrocarbon seeded ignition system. Unlike a pyrotechnic ignitor, the proposed system would allow the gas generation cycle to be terminated and reinitiated on demand.

Figure 6 shows the proposed demonstration experiment, where two micro-hybrid ignitors are used to thermally dissociate a $24 \%$ aqueous $H A N$ solution. In this experiment, since the aqueous $H A N$ solution has a very low vapor pressure, the ignitor oxidizer $(G O X)$ will also be used as the top-pressurant for the main propellant flow. For this application $\mathrm{GOX}$ is preferred to $\mathrm{N}_{2} \mathrm{O}$ as the working ignition fluid to allow for a more consistent top-pressure level. The GOX top pressure replaces the helium or nitrogen gas top pressure typically used for HAN-based thrusters. The effects of HAN concentration and fuel components on the gas-product exhaust temperatures and specific impulses will be investigated.

Different combustor geometries will be investigated. Of particular interest are side injections of the HAN water solution along the chamber walls. In this approach centrifugal forces will keep the liquid components of the mixture against the chamber walls and allow the water vapor in the chamber core to be more rapidly heated. This approach will also facilitate enhance heat transfer from the chamber walls to the HAN mixture once dissociation has begun. Finally, the potential for hydrocarbon seeding in the main combustion chamber will be investigated. Here the walls will be covered with an ABS liner that vaporizes as the HAN solution dissociates and acts as a fuel component for the motor. 


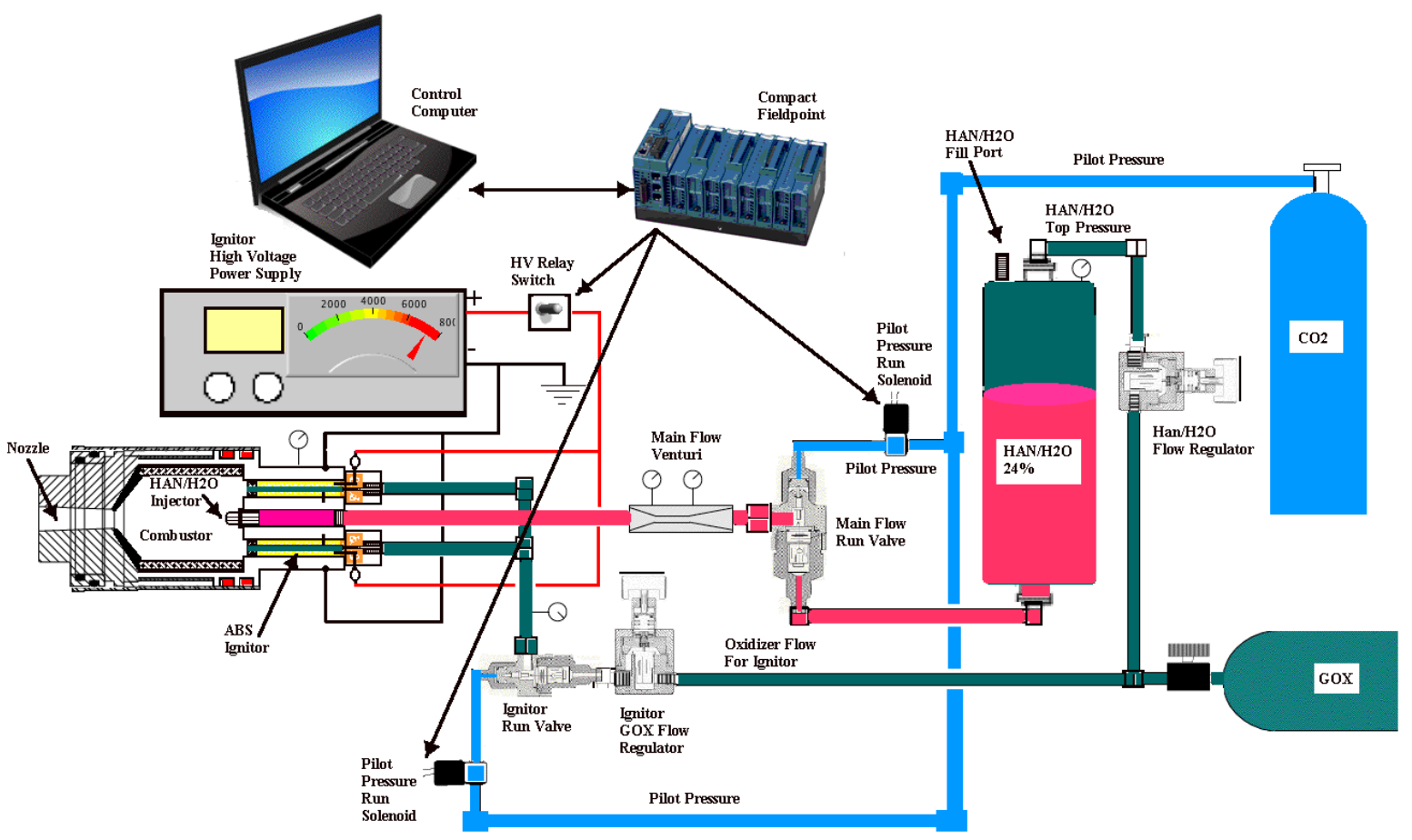

Figure 6. Micro-Hybrid Ignition of a $24 \%$ Aqueous HAN Solution.

Figure 7 shows the results of these calculations. Here the assumed chamber volume is $600 \mathrm{~cm}^{3}$, and the main chamber nozzle expansion ratio is 5:1. The ratio of the HAN/water to ignitor exhaust product mass flow is a key parameter, and must be less than 10:1 in order to overcome the latent of vaporization of the water. Based on Courthéoux's experiments, once the water vapor/HAN mixture within the chamber reaches $173 \mathrm{C}$, the mixture will thermally dissociate and self-sustaining combustion will occur. The simulation studies also predict that higher solutions with concentrations of HAN will reach dissociation temperatures significantly more quickly.
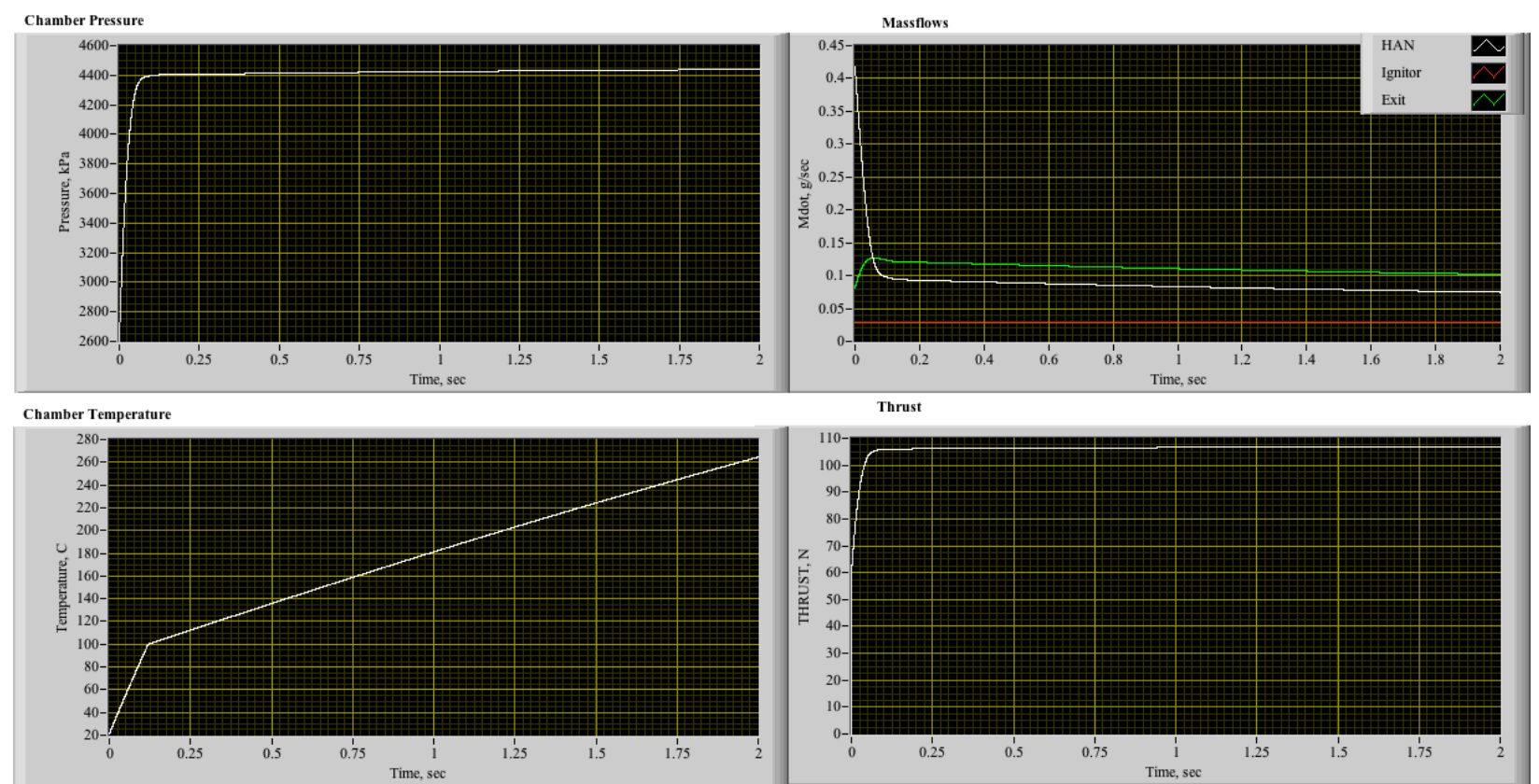

Figure 7. Predicted HAN/Water Solution Chamber Properties for Dissociation Experiment. 


\section{Conclusion}

The demonstrated capability of hydrocarbon-seeding for a motor ignition system is a significant step forward. The approach is singularly unique in the industry and has been proposed by no other source. This approach allows the simplicity of mono-propellant ignition system, while still providing the high-energy and performance of a bipropellant ignition system. The propellants, GOX and ABS are 100\% non-toxic, inert, and environmentally benign. This series of tests marks the first time that a hybrid motor has ever been ignited by anything other than a solidpropellant pyrotechnic charge or bi-propellant flame ignitor. The process worked seamlessly with the only limit to the number of available repeat firings being the amount of ABS seed material that can be fit into the injector cap. This approach to motor ignition also makes the system highly resistant to potential issues with Hazards of Electromagnetic Radiation to Ordnance (HERO). Nitrous oxide hybrid motors are typically difficult to ignite and usually require multiple solid-propellant charges burning for nearly a full second to initiate combustion, so this nonpyrotechnic ignition is quite an accomplishment.

The small ABS fuel segments used to "catalyze" the flow can be quickly and inexpensively fabricated using FDM rapid-prototyping machines; which stands in stark contrast to catalytic ignition systems that are "one-off" fabricated using expensive noble metals and supporting substrates. The electrostatic source used to initiate the combustion process can be provided inductively, and uses only a few joules per ignition. This value is contrasted with the typical pre-heat energy requirement of 8.25 Watts for 30 minutes with a total energy input of 14,850 Joules for the catalytic dissociation of the ECAPS LMP-103S ADN-based monopropellant.47,48

Development of the system as stand-alone "green" thruster offers the potential for cross-cutting applications. Such a small thruster system will enable multiple satellites be deployed nearly simultaneously by a single launch vehicle. Each propulsion unit will re-position the spacecraft into the proper orbit and then maintain the individual orbits to extend the mission lifetime. If fully developed to a point where small spacecraft can be deployed into LEO, properly re-positioned, and rapidly replaced using a multitude of available launch opportunities, this small propulsion unit will introduce a game changing technology to the science community and commercial space market. Because the oxidizer and fuel components are mixed only within the combustion chamber once the ignition is initiated, the system also retains the inherent safety of a hybrid rocket and can be piggy-backed with no overall mission risk increase to the primary payload, an excellent characteristic for secondary launch systems.

The proposed ignition technology is also applicable to a wide range of gas-generation systems where aqueous HAN solutions replace hydrazine as the working fluid. Example re-deployment applications include the Emergency Power Unit (EPU) on the F-16 fighter. In the case of an emergency failure the F-16 EPU uses the gases produced by the dissociated hydrazine to spin a small turbine provide emergency hydraulic and electrical power. Because the aqueous ADN or HAN solutions have significantly higher densities than hydrazine, this application would offer significantly longer run-times or reduced overall system volumes. By varying the HAN concentration within the mixture, the exhaust gas temperature can be moderated to insure a trade-off between ignition reliability and downstream component survivability.

\section{Bibliography}

\footnotetext{
${ }^{1}$ Whitmore, Stephen A., "Hydrocarbon-Seeded Monopropellant Thruster," Utah State University Technology Disclosure No. D12054, April 12, 2012, http://ipso.usu.edu/, [Retrieved 15 July, 2012].

2 Anon., “Total Propulsion Solutions,” AeroJet, Redmond Operations, 2006-H-3391, June 2007.

${ }^{3}$ Choudhary G, IIansen H, Donkin S, Kirman C. 1997. Toxicological Profile for Hydrazines. US Department of Health and Human Services Public Health Service Agency for Toxic Substances and Disease Registry (ATSDR), Atlanta GA, pp. 1-224.

${ }^{4}$ DeSain, John D., “Green Propulsion: Trends and perspectives,” Crosslink, http://www.aero.org/publications/crosslink/summer2011/04.html, [Retrieved 21 March, 2012].

${ }^{5}$ Anon., “Hazard Analysis of Commercial Space Transportation; Vol. 1: Operations, Vol. 2: Hazards, Vol. 3: Risk Analysis,” U.S. Dept. of Transportation, PB93-199040, Accession No. 00620693, May 1988.

${ }^{6}$ Zilliac, G., and Karabeyoglu, M. A., "Modeling of Propellant Tank Pressurization,” AIAA-2005-3549, 41st AIAA/ASME/SAE/ASEE Joint Propulsion Conference \& Exhibit, Tucson AZ, 10-13 July, 2005.

${ }^{7}$ Haeseler, D., Bombelli, V., Vuillermoz, P., Lo, R., Marée, T., \& Caramelli, F., “Green Propellant Propulsion Concepts for Space Transportation and Technology Development Needs," ESA SP-557, Proceedings of the 2nd International Conference on Green Propellants for Space Propulsion, Cagliari, Sardinia, Italy, 7-8 June 2004, p.4.1.

${ }^{8}$ Bombelli, V., "Economic Benefits for the Use of Non-toxic Monopropellants for Spacecraft Applications, AIAA-2003-4783,
} 
39th AIAA/ASME/SAE/ASEE Joint Propulsion Conference and Exhibit, Huntsville, AL, 20-23, July 2003.

${ }^{9}$ Wernimont, E. J., "System Trade Parameter Comparison of Monopropellants: Hydrogen Peroxide vs Hydrazine and Others," AIAA-2006-5235, 42 ${ }^{\text {nd }}$ AIAA/ASME/SAE/ASEE Joint Propulsion Conference \& Exhibit, Sacramento, CA, 9-12, July 2006.

${ }^{10}$ Anon., “Occupational Health Guidelines for Hydrogen Peroxide,” US Department of Health and Human Services Bulletin 0335, September, 1978, http:// www.cdc.gov/niosh/docs/81-123/pdfs/0335.pdf, [Retrieved 7 November 2012].

${ }^{11}$ Venkatachalam, S., Santhosh, G., Ninan, K. N. , "An Overview on the Synthetic Routes and Properties of Ammonium Dinitramide (ADN) and other Dinitramide Salts". J. Propellants, Explosives, Pyrotechnics, Vol. 29, No. 3, March, 2004, pp.178187.

${ }^{12}$ Nagamachi, M. Y., Oliveira, J. I., Kawamoto, A. M., and Dutra, R., C., “ADN - The new oxidizer around the corner for an environmentally friendly smokeless propellant,” J. of Aerospace Technology Management, Vol. 1, No. 2., December 2009, pp. 153-160.

${ }^{13}$ Rheingold, A. L., Cronin, J. T., Brill, T. B., and Ross, F. K., "Structure of Hydroxylammonium Nitrate (HAN) and the Deuterium Homolog,” Acta Crystallographica, Vol. 43, No. 1, 1987, pp. 402-404.

${ }^{14}$ Pembridge, andJ. R., Stedman, G., "Kinetics, Mechanism, and Stoicheiometry of the Oxidation of Hydroxylamine by Nitric Acid," J. of Chemical Society, Dalton Transactions, Issue 11, 1979, pp. 1657-1663.

${ }^{15}$ Handy, S., ed., Applications of Ionic Liquids in Science and Technology, InTech Publishing, New York, 2011, Chapt. 21, also available online http://www.intechopen.com/books/applications-of-ionic-liquids-in-science-and-technology, [Retrieved 7 November 2012].

${ }^{16}$ Anon., “SRI International,” URL: http://www.sri.com/about, [Retrieved 27 September 2012].

${ }^{17}$ Bottaro, J.C., Penwell, P.E., Schmitt, R.J., 1997, “1,1,3,3- Tetraoxo - 1,2,3-Triazapropene Anion, a New Oxy Anion of Nitrogen: The Dinitramide Anion and Its Salts”, J. Am. Chem. Soc., Vol. 119, pp. 9405-9410.

${ }^{18}$ Anon., A-ZET.org, "ECAPS, Moog and ATK Announce Partnership to Bring High Performance Green Propulsion (HPGP) Technology to the US Space Propulsion Market,” URL: http://www.a-zet.org/aerospace-industry-and-business-news/marketmonitor/393-ecaps-moog-and-atk-announce-partnership-to-bring-high-performance-green-propulsion-hpgp-technology-to-the-usspace-propulsion-market.html, [Retrieved 27 September 2012].

${ }^{19}$ Goldstein, Edward, “The Greening of Satellite Propulsion,” Aerospace America, February, 2012, pp. 26-28.

${ }^{20}$ Pokrupa, N., Anglo, K., and Svensson, O., "Spacecraft System Level Design with Regards to Incorporation of a New Green Propulsion System,” AIAA-2011- 6129, 46th AIAA/ASME/SAE/ASEE Joint Propulsion Conference and Exhibit, Sandiego, CA, July 31-Aug 3, 2011.

${ }^{21}$ Persson, M., Anflo, K., and Dinardi, A., “A Family of Thrusters For ADN-Based Monopropellant LMP-103S,” AIAA-20123815, 48th AIAA/ASME/SAE/ASEE Joint Propulsion Conference \& Exhibit 30 July - 01 August 2012, Atlanta, Georgia, 2012.

${ }^{22}$ Klein, N., and Stiefel, L., ed. "Liquid Propellants for Use in Guns,” , Gun Propulsion Technology, Progress in Astronautics and Aeronautics, Vol. 109, AIAA, Washington, D.C., 1988, Chapter 14.

${ }^{23}$ Anon., "Liquid Propellant 1846 Handbook," Jet Propulsion Laboratory, U.S. Department of the Army, ARDEC, Picatinny Arsenal, NJ, July, 1994.

${ }^{24}$ Freedman, E., and Stiefel, L., ed. “Thermodynamic Properties of Military Gun Propellants”, Gun Propulsion Technology, Progress in Astronautics and Aeronautics, Vol. 109, AIAA, Washington, D.C., 1988, Chapter 5.

${ }^{25}$ JanKovsky, R. S., HAN-Based Monopropellant Assessment for Spacecraft,” NASA TM 107287, (Also AIAA-96-2863), 32nd AIAA/ASME/SAE/ASEE Joint Propulsion Conference and Exhibit, Lake Nuena Vista, FL, July 1-3, 1996.

${ }^{26}$ Decker, M.M.; Klein N.; Freedman, E.; Leveritt, C.S.; Wojciechowski, J.Q.: "HAN- Based Liquid Gun Propellants: Physical Properties,” BRL-TR-2864, 1987.

${ }^{27}$ Meinhart, D., "Selection of Alternate Fuels for HAN-BASED Monopropellants," $27^{\text {th }}$ JANAFF PDCS and $16^{\text {th }}$ S\&EPS Joint Meeting, CPIA Pibl. 674, Vol. 1, April 1998, Pp. 143-147.

1. ${ }^{28}$ Hurlbert, E., Applewhite, J., Nguyen, T., Reed, B., Zhang, B., and Wang, Y., "Nontoxic Orbital Maneuvering and Reaction Control Systems for Reusable Spacecraft,” Journal of Propulsion and Power, Vol. 14, No. 5, 1998, pp. 676-687.

${ }^{29}$ Anon., “ Department of Defense Interface Standard, Eletromagnetic Environmental Effects requirements for Systems, MILSTD-464, http:// www.tscm.com/MIL-STD-464.pdf, [Retrieved 8 October 2012].

${ }^{30}$ Bonanos, A. M., Schetz, J. A., O'Brien, W. F., and Goyne, C. P., "Dual-Mode Combustion Experiments with an Integrated Aeroramp-Injector/Plasma-Torch Igniter", Journal of Propulsion and Power, Vol. 24, No. 2, March-April, 2008, pp. $267-273$.

${ }^{31}$ Anon., “SpaceX, Updates: February 2005-May 2005,” Space Exploration Technologies, URL: http://www.spacex.com/updates_archive.php?page=0205-0505, [Retrieved 11 October, 2012].

${ }^{32}$ Zube, D., Christofferson, S., Wücherer, E., and Reed, B., "Evaluation of HAN-Based Propellant Blends," 2003, AIAA Paper 2003-4643, 39th AIAA/ASME/SAE/ASEE Joint Propulsion Conference, Huntsville, AL, 20-23 July, 2003.

${ }^{33}$ Courthéoux, L., Eloirdi, R., Rossignol, S., Kappenstein, C., and Duprez, D., “Catalytic Decomposition of HAN-Water Binary 
Mixtures,” AIAA-2002-4027, 38th AIAA/ASME/SAE/ASEE Joint Propulsion Conference \& Exhibit, , Indianapolis IN, 7-10 July 2002.

${ }^{34}$ Oommen, C., Rajaraman, S., Chandru, R. A., Rajeev, R., "Catalytic Decomposition of Hydroxylammonium Nitrate Monopropellant,” 2011 International Conference on Chemistry and Chemical Process, IPCBEE vol.10, Singapore, 2011, http://www.ipcbee.com/vol10/39-V10034.pdf, [Retrieved 4 October 2012].

${ }^{35}$ Ren, X., Wang, A., Xu, D., Cong, Y., Wang, X., and Zhang, T., “Catalytic Decomposition of HAN-Based Monopropellant at Room Temperature over Ir/SiO2 Catalyst," SP-635, Ionic Liquids Session, "The 3rd International Conference on Green Propellant for Space Propulsion,” Futuroscope, France, 17-29 September, 2006.

${ }^{36}$ Ren, X., Li, M., Wang, A., Li, L., Wang, X., and Zhang, T., “Catalytic Decomposition of Hydroxyl Ammonium Nitrate at Room Temperature,” Chinese Journal of Catalysis, Vol. 28, No. 1, 2007, pp. 1-2, URL: http://www.chxb.cn/EN/Y2007/V28/I1/1, [retrieved 4 October 2012].

${ }^{37}$ Risha, G. A., Yetter, R. A. \& Yang, V. (2007). Electrolytic-induced decomposition and ignition of HAN-based liquid monopropellants," International Journal of Energetic Materials \& Chemical Propulsion, Vol. 6, No. 5, pp. 575-588,

${ }^{38}$ Meng, H., Khare, P., Risha, G. A., Yetter, R. A., and Yang, V., "Decomposition and Ignition of HAN-Based Monopropellant by Electrolysis," AIAA-2009-451, Including The New Horizons Forum and Aerospace Exposition AIAA 2009-451, Orlando, Florida, 5 - 8 January 2009.

${ }^{39}$ Khare, P., “Decomposition and Ignition of HAN-Based Monopropellants by Electrolysis,” MS Thesis,” Pennsylvania State University Graduate School, College of Engineering, May 2009.

${ }^{40}$ Kuo, B. H., “A Study on the Electrolytic Decomposition of HAN-Based Propellants for Microthruster Applications,” MS Thesis,” Pennsylvania State University Graduate School, College of Engineering, December 2010.

${ }^{41} \mathrm{Wu}$, M. H., Yetter, R., and Yang, V., "Development and Characterization of Ceramic Micro Chemical Propulsion and Combustion Systems,” AIAA-2008-966, 46th AIAA Aerospace Sciences Meeting and Exhibit AIAA 2008-966, Reno, Nevada, 7 - 10 January 2008.

42 Peterson, Z. W., Eilers, S., A., and Whitmore, S. A., "Analytical and Experimental Comparisons of HTPB and ABS as Hybrid

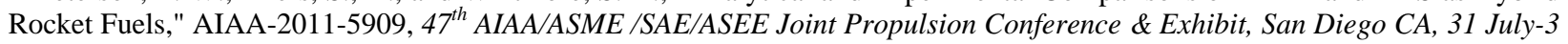
August 2011.

${ }^{43}$ Shugg, W. T., Handbook of Electrical and Insulating Materials, Van Nostrand Reinhold, New York, 1986.

44 Anon., "High Power 8C-30C Series, Single Output High Voltage DC/DC Modules," UltraVolt, Inc., URL: http://www.ultravolt.com/uv_docs/HP8C-30CDS.pdf, [Retrieved 9 October 2012].

${ }^{45}$ Pro98 ${ }^{\circledR}$ High-Power Rocket Motor Systems Cesaroni Rockets, http://www.pro38.com/pdfs/Pro98_Instructions.pdf, [Retrieved 13 November 2010.]

${ }^{46}$ Peterson, Z. W., Eilers, S., A., and Whitmore, S. A., "Analytical and Experimental Comparisons of HTPB and ABS as Hybrid

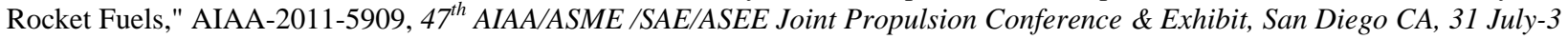
August 2011.

${ }^{47}$ Persson, M., Anflo, K., and Dinardi, A., “A Family of Thrusters For ADN-Based Monopropellant LMP-103S,” AIAA-20123815, 48th AIAA/ASME/SAE/ASEE Joint Propulsion Conference \& Exhibit, Atlanta, Georgia, 30 July - 01 August 2012.

48 Anflo, K., and Crowe, B., "In-Space Demonstration of an ADN-based Propulsion System,” AIAA-2011-5832, 47th AIAA/ASME/SAE/ASEE Joint Propulsion Conference \& Exhibit 31, San Diego, California, July - 03 August 2011 